\title{
Rose Bengal Test and Complement Fixation Test to Detect Human Brucellosis in Occupationally Exposed Groups at Cilawu District, Garut
}

\author{
$\underline{\text { Risqa Novita }}$ \\ Centre for Biomedic and Basic Health Technology, NIHRD \\ Ministry of Health of Republic Indonesia \\ Corresponding author:rn_smile01@yahoo.com
}

\begin{abstract}
Human brucellosis is a neglected zoonoses disease in Indonesia. The data on human brucellosis prevalence is limited. Brucellosis infects human from infected animals by direct contact, drink milk from infected animals and breath the contaminated air. Farmers, dairy workers, veterinarians and people who work at the farm have high risk for infected human brucellosis. Limited studies have been undertaken on human brucellosis especially in occupationally exposed groups. This study was conducted to estimate the seroprevalence of human brucellosis among occupationally exposed group in Cilawu sub district, Garut by serological tests (RBT and CFT). The study was carried out in rural area, in Cilawu District. The samples were based on estimated proportion test. We selected 57 respondents with inclusion criterias. Blood samples were collected from 57 occupationally exposed individuals. The blood samples process to serum by centrifuse in $3000 \mathrm{rpm}$ for 10 minutes. The serum samples were screened for the presence of anti-brucellar antibodies by Rose Bengal Test (RBT) and confirmated test by Complement Fixation Test (CFT). 7.01 $\%$ human were positive by RBT. For confirmation test, we used CFT. The result of CFT was $5.3 \%$ positive. The major risk factors was dairy workers among the occupational exposed groups. The studied population were exposed to Brucella spp infection. Regular screenings for brucellosis and awareness programmes to control brucellosis in occupationally exposed groups are necessary.
\end{abstract}

Keywords : Human brucellosis, neglected zoonoses, RBT, CFT

\section{INTRODUCTION}

The World Health Organization (WHO) listed brucellosis as neglected zoonotic diseases. Human brucellosis is a major bacterial zoonosis reported worldwide. Brucellosis remains endemic in many regions of the world including Latin America, Africa, Asia, the Middle East and the Mediterranean basin. Indonesia is endemic brucellosis in animal, only 8 provinces of 34 provinces which free from brucellosis. Brucellosis is a recognized occupational hazard which is rarely diagnosed in most health facilities in Indonesia. Very few study have been done to assess the prevalence of brucellosis in dairy workers in Indonesia. The RBT is a cheap and effective test which could be distributed to primary, secondary and tertiary health centers at low cost, enabling health practitioners to screen patients presenting with non-specific symptoms compatible with brucellosis. 


\section{The objective and benefit}

The objective : To examine the usefulness of classical serological methods (RBT and CFT) for detect human brucellosis

Benefit : This study will give the information about the usefulness of RBT, additional brucellosis cases to those presenting to referral tertiary hospitals in the capital or health services abroad could be diagnosed and treated.

\section{METHODS}

Study area: The dairy livestock in Cilawu Sub District,Garut

Study design: A cross sectional study was conducted on August 2017

Sample :

The sample size for dairy workers were determined based on the recent zero prevalence studies of brucellosis in Malaysia of $14.9 \%$ was considered to determine sample size.

examined were increased to 156 .

The formula for calculating sample size:

$n=[Z 21-\alpha / 2 p(1-p) X$ Deff

$\mathrm{d} 2$

Blood samples were taken from 57 respondents. The sera were submitted to The Infectious Laboratory of NIHRD.

\section{Blood samples}

Blood samples were taken by qualified medical personnel. Approximately 3-5 $\mathrm{ml}$ of venous blood was drawn from each respondents using vacutainer tube (BD vacutate, UK), syringe and needles using aseptic techniques. The samples were placed at an inclined position and allowed to clot for $1-2 \mathrm{~h}$ at room temperature. Then stored overnight horizontally at $4{ }^{\circ} \mathrm{C}$, the serum was separated from the clot by centrifugation at $2500 \mathrm{rpm}$ for $10 \mathrm{~min}$ at room temperature.

Serological tests:

\section{Rose Bengal Test}

Equal volumes of test serum and Brucella abortus antigen Idvet, as $30 \mu 1$ approximately were placed alongside in a plate and then mixed thoroughly with tooth pick then rocked for 8 min with hands. The results were interpreted according to the presence and degree of agglutination.Samples with no agglutination (0) were recorded as negative while those with ,+++ , and +++ were recorded as positive.

\section{Complement Fixation Test}

Result positive using RBT were further confirmed using CFT which has two steps. The first step is antigen, test serum and complement are mixed and incubated. The second step is an indicator system which consists of sheep red blood cells (SRBC) and amboceptor that sensitizes red blood cells to the action of the complements. If the test serum contains antibodies to Brucella, an antigen-antibody complex is formed; the complement is used up and no lysis of SRBC occurs. If the test serum does not contain Brucella antibodies (negative reaction), the complement will not be fixed and lysis of SRBC would occur.

\section{Data collection}

Results from serological tests was analyzed descriptively. 


\section{RESULTS}

57 human sera samples screened with RBT, 4 (7.02\%) were found positive, further confirmed with CFT where $3(5.3 \%)$ were confirmed positive.

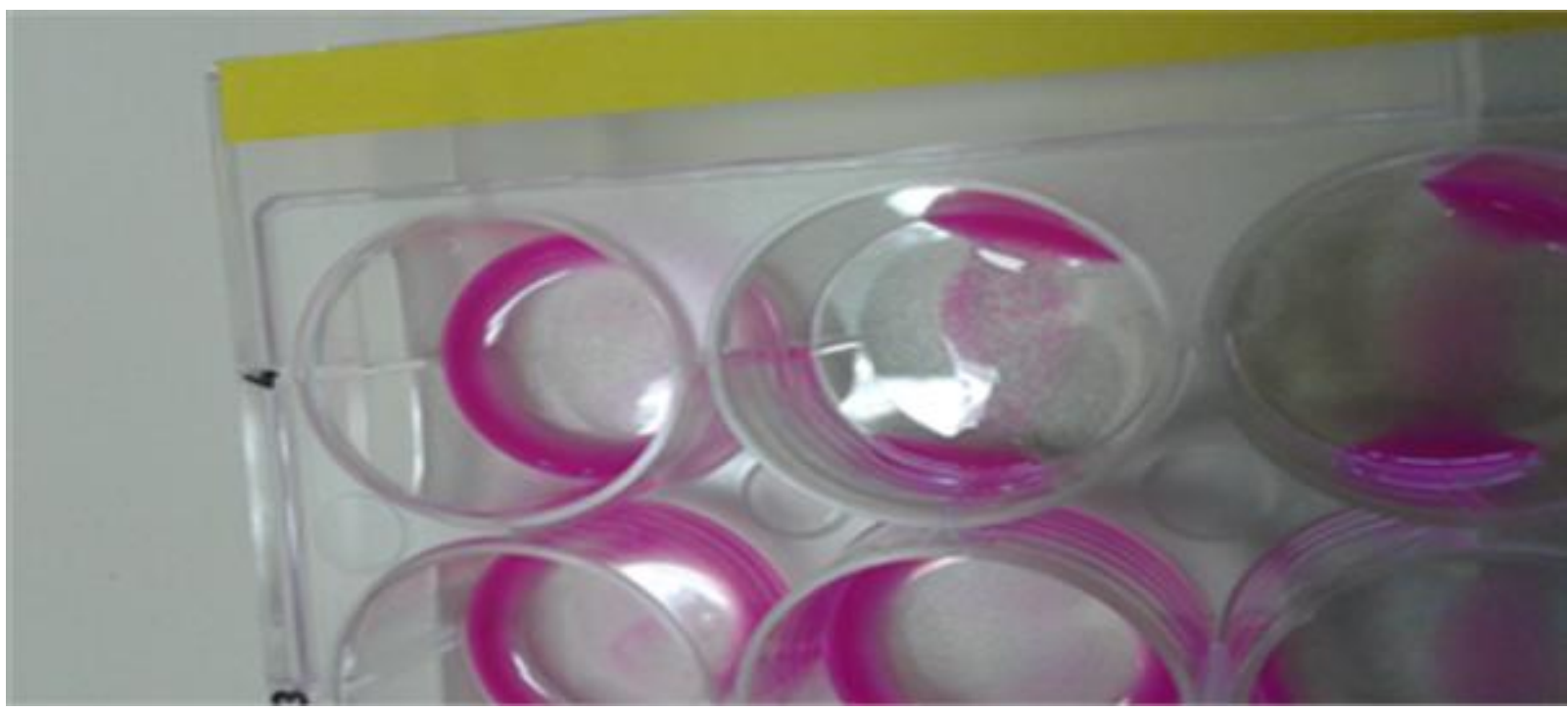

Figure 1. Rose Bengal Test

Table 1. Serology test results

\begin{tabular}{rcccc}
\hline \multicolumn{1}{c}{ Respondents } & \multicolumn{2}{c}{ RBT } & \multicolumn{2}{c}{ CFT } \\
\hline \multirow{2}{*}{57 (Garut) } & $\begin{array}{l}\text { Positive } \\
\text { (people) }\end{array}$ & $\begin{array}{l}\text { Negative } \\
\text { (people) }\end{array}$ & $\begin{array}{l}\text { Positive } \\
\text { (people) }\end{array}$ & $\begin{array}{c}\text { Negative } \\
\text { (people) }\end{array}$ \\
\cline { 2 - 5 } & $4(7,01 \%)$ & $53(92,9 \%)$ & $3(5,3 \%)$ & $54(94,7 \%)$ \\
\hline
\end{tabular}

We did not used ELISA as serological test, which has sensitivity and specificity higher than RBT but more expensive.

\section{CONCLUSIONS}

RBT is a useful test for diagnosis of human brucellosis because it needs no complicated infrastructure, cheap, highly sensitive and easily adaptable to serum dilutions

\section{AKNOWLEDGEMENT}

The authors would like to acknowledge the Centre of for funding this study. We are also thankful to the dairy workers for participation in the study. 


\section{REFERENCES}

TsegayAmanuel ,GetachewTuli, Tesfu Kassa and Nigatu Kebede. Seroprevalence and risk factors of brucellosis in abattoir workers at DebreZeit and Modjo export abattoir, Central Ethiopia. BMC Infectious Diseases. 2017: 17:101;1-8.

Diaz Ramon, Aurora Casanova, Javier Ariza,and Ignacio Moriyo. The Rose Bengal Test in Human Brucellosis: A Neglected Test for the Diagnosis of a Neglected Disease. PLOS Neglected Tropical Disease. 2011:5(4); 1-7.

Buzgan T, Karahocagil MK, Irmak H, Baran AI, Karsen H, Evirgen O, et al. Clinical manifestations and complications in 1028 cases of brucellosis: a retrospective evaluation and review of the literature. Int J Infect Dis 2010;14:e469-78.

Franco MP, Mulder M, Gilman RH, Smits HL. Human brucellosis. Lancet Infect Dis 2007; 7:775-86. 